\title{
Choroidal Tuberculoma in a Healthy Immunocompetent Patient
}

\author{
Hara Maya Gurung ${ }^{\otimes}$, Krishna Gurung ${ }^{1}$, Anju Gurung ${ }^{1}$, Indraman Maharjan ${ }^{1}$, Eliya Shrestha ${ }^{1}$, Babita Gurung ${ }^{1}$, \\ Hari Bikram Adhikari' ${ }^{1}$, Saroj Prasad Nemkul ${ }^{1}$ \\ ${ }^{1}$ Himalaya Eye Hospital, Gharipatan, Pokhara, Nepal
}

\begin{abstract}
Introduction: Ocular tuberculosis as choroidal tuberculoma is a rare event. It creates a clinical diagnostic dilemma when there is no systemic involvement.

Case: A 22-year-old man presented with the chief complaints of discomfort and blurring of vision of right eye for one week. On fundus examination under mydriatics of his right eye, a solitary mass which measured approximately 2DD (Disc Diameter) was appreciated at the superotemporal quadrant with the surrounding localized retinal detachment. Choroidal tuberculoma was suspected by a positive Mantoux test. Physician consultation and laboratory investigations ruled out the pulmonary and systemic manifestation of tuberculosis and other aetiology. Anti-tubercular treatment was started and this led to the improvement of vision and shrinkage of the choroidal mass into a flat chorioretinal scar at 3 months of anti-tubercular treatment .

Conclusion: Solitary choroidal tuberculoma though rare, can occur in a healthy, immunocompetent patient.

Key words: Anti-tubercular treatment, Choroidal tuberculoma, Mantoux test.
\end{abstract}

\section{INTRODUCTION}

Intraocular tuberculosis may present rarely as a large tuberculoma (Mansour et al, 1990). The location of the tuberculoma may vary anywhere in the choroid - in a juxtapapillary location, posterior pole or the equator. Generally, the tuberculoma occurs as a large single mass and mimics a tumor. Retinal folds or retinal detachment may be seen on the surface of tuberculoma (Gupta V et al, 2007). Rarely, choroidal tuberculoma may occur in a patient with no systemic disease (Berinstein et al, 1997). We hereby make a case report of choroidal tuberculoma in a healthy, immunocompetent patient.

$\begin{array}{ll}\text { Financial Interest : Nil } & \text { Received : 21.01.2021 } \\ \text { Conflict of Interest : Nil } & \text { Accepted : 20.05.2021 } \\ \text { Corresponding Author } & \\ \text { Dr. Hara Maya Gurung } & \\ \text { Himalaya Eye Hospital, } & \\ \text { Gharipatan, Pokhara, Nepal. } & \\ \text { E-mail: harimaya32@gmail.com } & \\ \text { Contact: +977 9846169647 } & \end{array}$

Access this article online

Website: www.nepjol.info/index.php/NEPJOPH DOI: https://doi.org/10.3126/nepjoph.v13i2.34049 Copyright $\odot 2021$ Nepal Ophthalmic Society ISSN: 2072-6805, E-ISSN: 2091-0320

This work is licensed under a Creative Commons Attribution-NonCommercial-NoDerivatives 4.0 International License (CC BY-NC-ND). 
CASE

A 22-year-old man presented with the chief complaints of discomfort and diminution of vision in the right eye.

He was apparently healthy. There was no history of exposure to tuberculosis. His childhood immunization schedule including BCG vaccination was completed.

On examination, vision was 6/36 OD and 6/9 OS. Both anterior and posterior segment examination of the left eye was within normal limits. On dilated fundus examination of his right eye, a single, yellow, subretinal lesion measuring around $3 \mathrm{~mm}$ (2 disc diameter) with a surrounding retinal detachment was appreciated at the superotemporal quadrant (Figure 1). USG B scan showed a dome shaped choroidal lesion with low to medium internal reflectivity and retinal detachment (Figure 2). There was a diffuse hyperfluorescence in the early phase and pooling of dye in the late phase in Fundus Fluorescein Angiography (FFA) (Figure 3).

Routine blood tests for uveitis - complete blood count (CBC), erythrocyte sedimentation rate (ESR), serum angiotensin converting enzyme (ACE) and serum calcium were all within normal limits. Antinuclear antibody (ANA), Venereal disease research laboratory test (VDRL), Human immunodeficiency virus (HIV) and Hepatitis

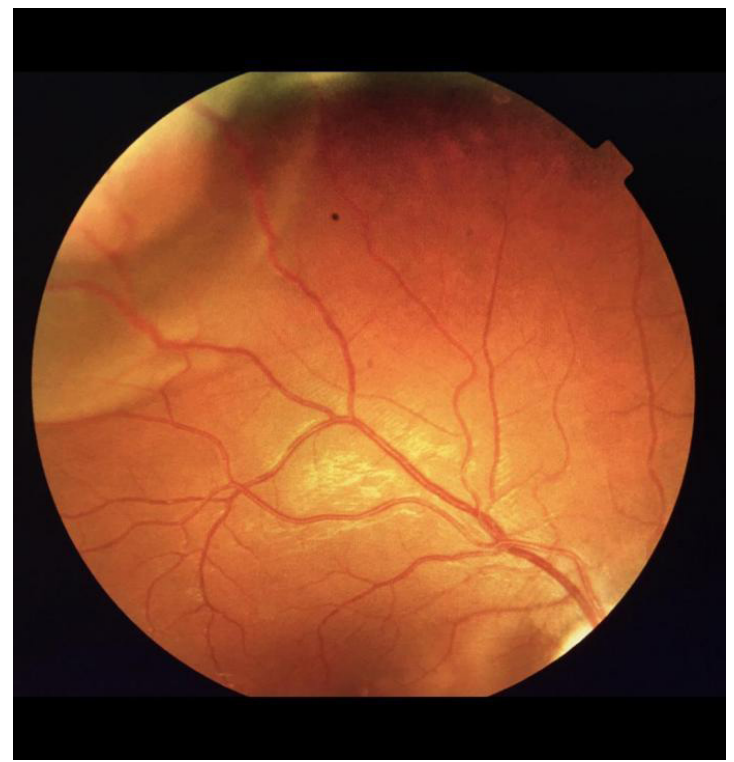

Figure 1: Choroidal mass with surrounding retinal detachment at the superotemporal quadrant on first examination.

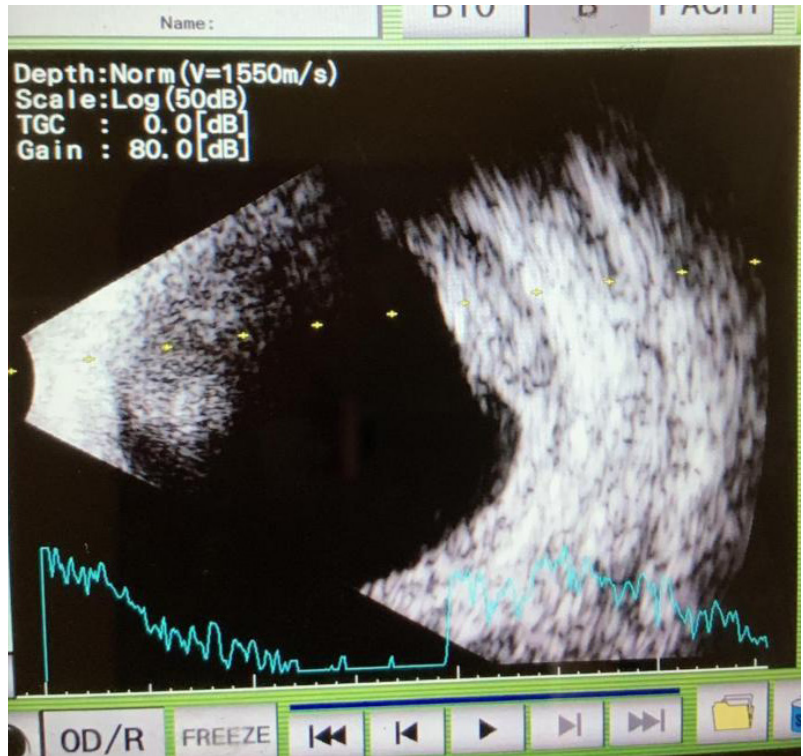

Figure 2: USG B scan of the choroidal lesion. 
\begin{tabular}{l|l} 
Curung HM et al \\
Choroidal Tuberculoma in a Healthy Individual \\
Nepal J Ophthalmol 2021; Vol 13 (26): 202-6
\end{tabular}

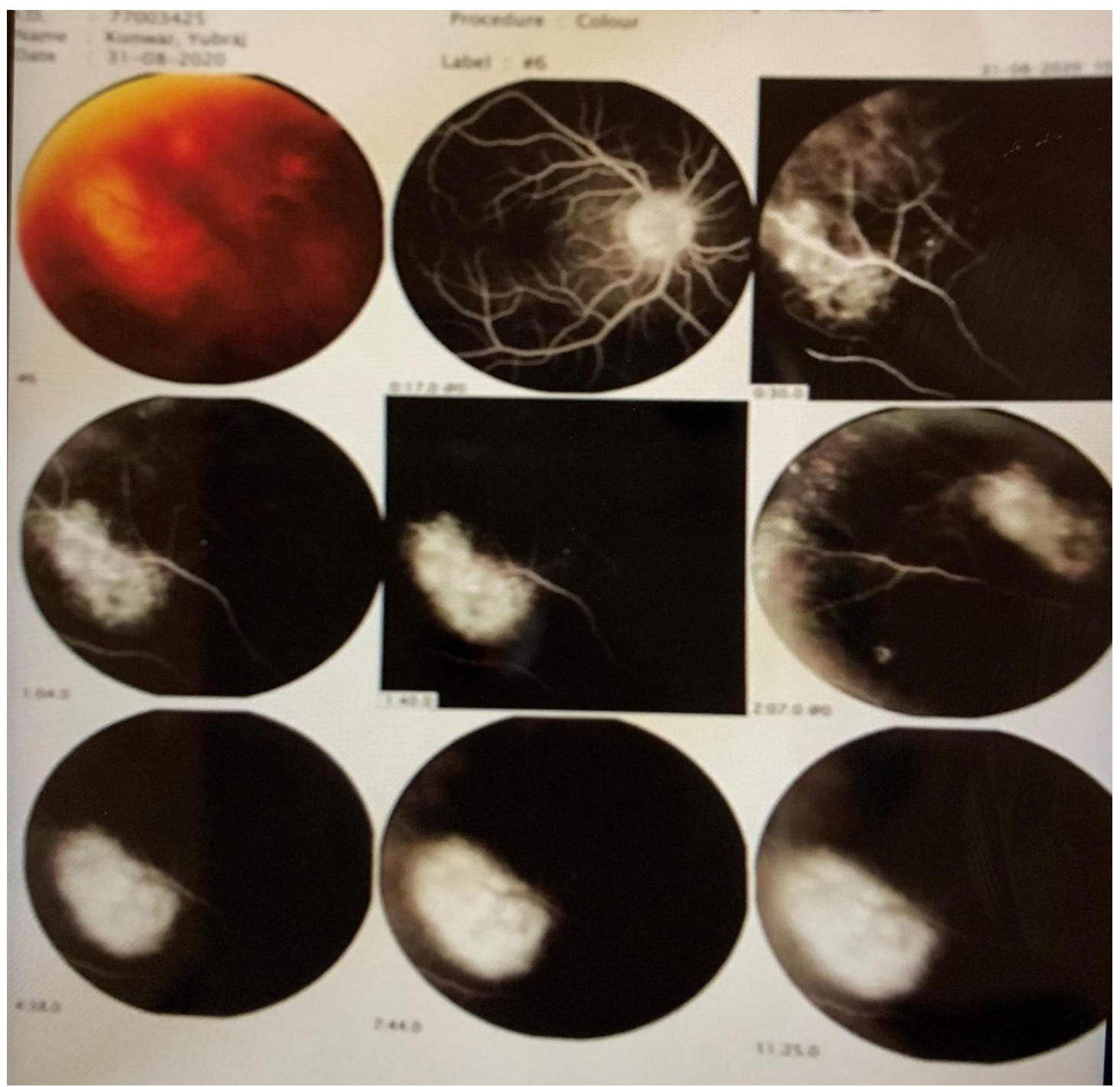

Figure 3: FFA showing diffuse hyperfluorescence in the early and pooling of dye in the late phase.

B surface antigen (HBsAg) were negative except for Mantoux test - a purified protein derivative skin test. It was positive with the induration of $15 \mathrm{~mm}$. The patient was referred to a physician for systemic assessment and further investigation. Chest X-Ray was normal, sputum for Acid Fast Bacilli in consecutive three days was negative. There was no evidence of systemic or pulmonary tuberculosis (TB).
Based upon these findings we made a diagnosis of a solitary choroidal tuberculoma in a healthy, immunocompetent individual. Anti-tubercular Treatment (ATT ) - 2 HRZE + 7 HRE + Tablet Pyridoxine 10mg ( 2 months of Isoniazid, Rifampicin, Pyrazinamide and Ethambutol followed by 7 months of Isoniazid, Rifampicin and Ethambutol) was started by the physician at the Regional Tuberculosis Center (RTC), 


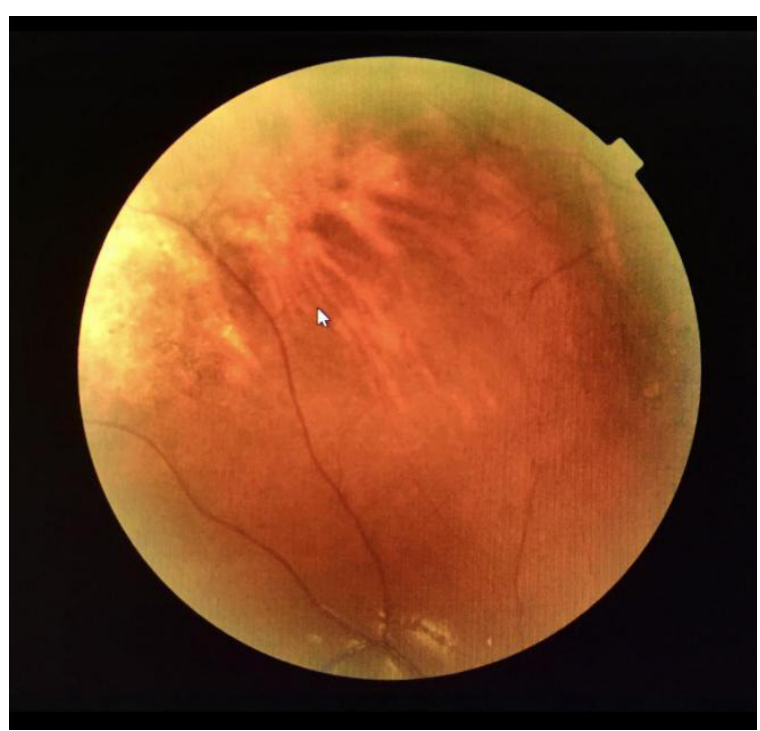

Figure 4: Chorioretinal scar seen 3 months after anti-tubercular treatment.

Pokhara. There was a subsequent improvement in the patient's symptom and resolution of the choroidal tuberculoma to a scar at three months of ATT (Figure 4). The best corrected visual acuity of both eyes showed $6 / 6$.

\section{DISCUSSION}

Ocular tuberculosis is rare. It comprises only $1 \%$ of total tuberculosis cases (Arej N et al, 2016; Bodaghi B et al, 2000). Ocular tuberculosis occurs either in the presence or absence of systemic tuberculosis. Most commonly it presents as posterior uveitis, especially as multiple choroidal tubercles. Ocular tuberculosis as a large choroidal tuberculoma is a rare event (Arej $\mathrm{N}$ et al, 2016).

The tubercle bacilli multiply within a tuberculoma that result in tissue destruction through liquefactive necrosis with a surrounding exudative retinal detachment (Arej $\mathrm{N}$ et al, 2016). Diagnosis is done clinically, thorough evaluation of the system and treatment response. Differential diagnosis like amelanotic choroidal melanoma, choroidal metastasis can be ruled out by investigative tools like FFA and USG B-scan (Arej N et al, 2016; Levecq LJ et al, 2005; Berinstein et al, 1997). Proper diagnosis and treatment leads to resolution of choroidal tuberculoma and improvement in visual acuity. Anti-tubercular treatment for a period of 6-12 months is considered a standard therapy. In advanced disease, though reduction in inflammation is seen, complete resolution of symptoms may not occur (Arej $\mathrm{N}$ et al, 2016; Zhang $M$ et al, 2012). In our case, our patient showed a good clinical response to treatment. It was demonstrated by the resolution of symptoms and shrinkage of the choroidal tuberculoma to a flat scar in three months of treatment with ATT. 


\section{CONCLUSION}

Choroidal tuberculoma, though rare, can occur in a healthy individual. So, being vigilant in the diagnosis and treatment plays an important role in saving the vision of patients.

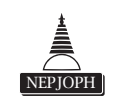

\section{REFERENCES}

Arej N, Fadlallah A, Chelala E (2016). Choroidal Tuberculoma as a presenting sign of tuberculosis. International Medical Case Reports Journal; 9:365-368. doi: 10.2147/IMCRJ.S119703; PMid:27956845

Berinstein DM, Gentile RC, McCormick SA, Walsh JB (1997). Primary Choroidal Tuberculoma. Archives of Ophthalmology; 115:430-431. doi: 10.1001/archopht.1997.01100150432025; PMid:9076224

Bodaghi B, LeHoang P (2000). Ocular tuberculosis. Current Opinion in Ophthalmology; 11:443-448. doi: 10.1097/00055735-200012000-00010; PMid:11141639

Gupta V, Gupta A, Rao NA (2007). Intraocular Tuberculosis - An Update. Survey of Ophthalmology; 52:561-587. doi: 10.1016/j.survophthal.2007.08.015; PMid:18029267

Levecq LJ, Potter PD (2005). Solitary Choroidal Tuberculoma in an Immunocompetent Patient. Archives of Ophthalmology; 123:864-866. doi: 10.1001/archopht.123.6.864; PMid:15955992

Mansour AM, Haymond R (1990). Choroidal tuberculomas without evidence of extraocular tuberculosis. Graefe's Arch Clinical and Experimental Ophthalmology; 228:382-383. doi: 10.1007/BF00920066; PMid:2401424

Zhang M, Zhang J, Liu Y (2012). Clinical Presentations and Therapeutic Effects of Presumed Choroidal Tuberculosis. The Journal of Retinal and Vitreous Diseases; 32(4):805-813. doi: 10.1097/IAE.0b013e3182215b5e; PMid:21878856 